gen. Attempts to remove these gases by the addition of silicon, aluminium, titanium and other metals which combine with the gases, produce slags which are often difficult to separate from the metal, and are often harmful to the refractory lining of the furnace. Subjecting motals to vacuum conditions removes these gases as well as gaseous carbon compounds. The process is based on the fact that the solubility of gases in metals is directly proportional to the gas pressure in the system. Satisfactory degasification does not necessarily require a high degree of vacuum, and good results were obtained at 1-0.01 mm. of mercury. Besides small-scale operations on high melting-point metals and their alloys, large-scale production of cast stoel under vacuum conditions has been successfully tried in the U.S.S.R. About fifteen years ago A. M. Samarin and L. M. Novik designed a vacuum installation for large steel containers and ingot moulds. This process is particularly important in the case of Bessemer steel operations, in which degasification for ten to fifteen minutes reduces the amount of nitrogen by 30-50 per cent and the amount of oxygen by a factor botween 4 and 10.

\section{Metallurgy and Ceramics in the United States}

SINCE 1950 the number of graduates in metallurgical engineering and ceramics in the United States has fallen by half, and although some 500 graduate annually in metallurgical engineering, on a conservative estimate $1,000-1,500$ are required annually for the next five years. The American Society of Metals, the American Ceramic Society and the American Institute of Mining, Metallurgical and Petroleum Engineers have accordingly appointed a special committee on man-power for the metallurgy and ceramics professions which has already organized three study groups. One study group is exploring the possibility of a national scholarship programme in industry and the others will seek to make more information available about the opportunities in these professions at high-school level and to adult education organizations.

\section{Archives of the Royal Society}

A GUIDE to the archives of the Royal Society and to other manuscripts in its possession, prepared by Mr. R. K. Bluhm for Notes and Records of the Royal Society (August 1956), has been reprinted and issued as a pamphlet. It gives a general summary of the Society's archives and the other manuscripts in its possession, showing in what manner they are catalogued and what form the catalogues take. The word 'archive' is construed to mean any minute of a meeting of the Society, its Council or its committees; any letter or document addressed to or coming from the Society or its officers in their official capacity; any list or schedule of its property and any ledger or register of its books, instruments or the like. The non-archive manuscripts consist chiefly of collections of the correspondence of men of science, and various miscellaneous items. The guide is not in general concerned with material dating from the present century. Brief descriptions of the main series or collections of manuscripts are included.

\section{H. Blackman Research Studentships}

THE East Malling Research Station Association has instituted the annual award of a research studentship which should be of considerable interest. These studentships, named after Prof. V. H. Blackman in recognition of his outstanding services to the Research Station for more than forty years, and of the great influence he exerted upon the developments of studies in the physiology of crop plants, have a value of $£ 500$ a year (tax free). They are tenable at East Malling Research Station and will provide unusually wide opportunities for training in the research methods appropriate to research on perennial fruit plants. At East Malling there are nine well-equipped research sections (pomology, statistics, physiology, biochemistry, fruit nutrition, plant analysis, plant pathology, entomology, and plant protective chemistry), and it is intended that the students shall develop their scientific experience on as wide a basis as possible during their three year's tenure. It is hoped that these studentships will provide a most fruitful impotus towards enhanced collaboration between crop research stations and university departments, as well as extending the opportunities of training and research for young graduates of outstanding merit.

\section{Announcements}

Sir Ian Cluntes Ross, chairman of the Commonwealth Scientific and Industrial Research Organization, Australia, has been awarded the Gold Medal of the Royal Agricultural Society of England. The Medal is awarded from time to time "for distinguished services to agriculture either in practice or in science". The award carries with it honorary membership of the Society.

Dr. L. E. ORGEL, assistant director of research in the Department of Organic and Inorganic Chemistry (Sub-Department of Theoretical Chemistry), University of Cambridge, has been awarded the Harrison Memorial Prize for 1956 of the Chemical Society, in consideration of his contribution to the development of theoretical chemistry published during the five years 1952-506.

THE following appointments in the University of Leeds have been announced: Mr. C. J. Black, to be senior agricultural economist in the Department of Agriculture; Mr. I. Codd, to be lecturer in the Department of Metallurgy; Dr. E. W. Worrall, to be lecturer in ceramies in the Department of Gas Engineering and General Fuel Science with Ceramics.

Sir Lawrence Bragg will deliver the fourth Trotter-Paterson Memorial Lecture to the Illuminating Engineering Society at the Royal Institution on February 11. The Lecture is entitled "Some Experiments on the Interference of Waves". Tickets can be obtained from the Secretary, Illuminating Engineering Society, 32 Victoria Street, London, S.W.1.

Applicatrons are invited for the Kathleen Schlesinger Fellowship, tenable at the National Hospital for Diseases of the Nervous System, London. Preference will be given to candidates proposing to investigate degenerative diseases of the brain and central nervous system, including biochemical abnormalities if so desired. The stipend will be within the range $£ 700-£ 1,000$ per annum. Further details can be obtained from the Secretary, Medical Research Council, 38 Old Queen Street, London, S.W.1.

ErratuM.- - In the obituary notice of Mr. John Evershed in Nature of December 15, p. 1323, the maiden name of Mr. Evershed's first wife is given incorrectly; she was Miss Mary Acworth Orr. 